\title{
Presence of the Tn Antigen on Hematopoietic Progenitors from Patients with the Tn Syndrome
}

\author{
William Vainchenker, Giovanna Vinci, Ugo Testa, Annie Henri, Antonio Tabilio, \\ Marie-Pierre Fache, Henri Rochant, and Jean-Pierre Cartron \\ INSERM U.91, Hôpital Henri Mondor, 94010 Creteil, France; Laboratoire de Cytofluorométrie \\ Analytique \& Séparative, 94270 Villejuif, France; and Laboratoire de Biochimie \\ Génétique, INSERM U.76, Centre National de Transfusion Sanguine, 75015 Paris, France
}

\section{Abstract}

The Tn syndrome is an acquired clonal disorder characterized by the exposure of a normally hidden determinant, the Tn antigen, on the surface of human erythrocytes, platelets, granulocytes, and lymphocytes. Two distinct populations, Tn positive $\left(\mathrm{Tn}^{+}\right)$and $\mathrm{Tn}$ negative $\left(\mathrm{Tn}^{-}\right)$, of mature hemopoietic cells are present in $\mathbf{T n}$ patients. To determine whether the $\mathbf{T n}$ antigen is already expressed on erythroid, myeloid, and pluripotent progenitors, light-density mononuclear blood cells from two patients with this syndrome were separated by fluorescentactivated cell sorting and by affinity chromatography into $\mathbf{T n}^{+}$ and $\mathrm{Tn}^{-}$fractions, using their binding properties to Helix pomatia agglutinin (HPA). Burst-forming-unit erythroid (BFUE), colony-forming-unit granulocyte/macrophage (CFU-GM), and mixed colony-forming-unit (CFU-GEMM) cells were assayed in plasma clot cultures. After 12-14 d of culture, colonies were studied by a double fluorescent labeling procedure. First, a fluorescein-conjugated HPA permitted evaluation of the presence or absence of the $T n$ antigen at the surface of the cells composing each colony, and second, the binding of a murine monoclonal antibody against either glycophorin $A$ (LICR-LON-R10) or against a myeloid antigen (80H5), revealed by an indirect fluorescent procedure, was used to establish the erythroid or myeloid origin of each cell. $\mathrm{The}^{\mathrm{Tn}^{+}}$fraction obtained by cell sorting gave rise to nearly $100 \% \mathrm{Tn}^{+}$colonies composed exclusively of cells bearing this antigen. The reverse was observed for the $\mathrm{Tn}^{-}$cell fraction. These results demonstrate that in the Tn syndrome, BFU-E, CFU-GM, and CFU-GEMM of the $\mathrm{Tn}^{+}$clone express the $\mathrm{Tn}$ antigen at this early stage of differentiation.

\section{Introduction}

The Tn syndrome is an acquired disorder first identified by the polyagglutinability of erythrocytes following exposure of the cryptoantigen Tn at the surface of red cells $(1,2)$. This disorder may occur in apparently healthy individuals or may be associated with a mild hemolytic anemia, leukopenia, or thrombocytopenia, but has also been described in some acute leukemias or myeloproliferative diseases $(3,4,5)$.

The biochemical basis of Tn activation is now well char-

Address correspondence to Dr. Cartron, INSERM U.76, C.N.T.S., 6 rue Alexandre Cabanel, 75015 Paris, France. 1984.

Received for publication 23 July 1984 and in revised form 1 October

J. Clin. Invest.

(C) The American Society for Clinical Investigation, Inc.

0021-9738/85/02/0541/06 \$1.00

Volume 75, February 1985, 541-546 acterized and corresponds to the exposure of an $\mathrm{N}$-acetylgalactosamine residue carried by cell surface glycoproteins (6), which arise from a selective loss of a 3- $\beta$-D-galactosyltransferase ( $\mathrm{T}$ transferase) activity in $\mathrm{Tn}$ positive $\left(\mathrm{Tn}^{+}\right)^{1}$ cells $(7,8,9)$. The Tn antigen has been detected at the cell surface of erythrocytes and more recently on granulocytes, monocytes, platelets, B lymphocytes, and $\mathrm{T}$ lymphocytes by the binding of a fluorescent Helix pomatia agglutinin (HPA), a reagent known to interact strongly with $N$-acetylgalactosamine (10, 11). Interestingly, two distinct populations of peripheral blood cells, $\mathrm{Tn}^{+}$and $\mathrm{Tn}$ negative $\left(\mathrm{Tn}^{-}\right)$, are typically observed in patients with the Tn syndrome. Recently we have shown that the Tn condition was a clonal disease since a sizeable fraction of erythroid, granulocytic, or megakaryocytic colonies grown from the hemopoietic precursors seemed to consist exclusively of either $\mathrm{Tn}^{+}$or $\mathrm{Tn}^{-}$cells (10). It was therefore proposed that this syndrome was a clonal disorder in which a somatic mutation had occurred at the level of a pluripotent stem cell common to the myeloid B and T lymphoid lineages (11).

The purpose of this study was to investigate whether the Tn antigen was already expressed at very early stages of differentiation, i.e., on the erythroid, myeloid, and pluripotent progenitors that give rise to $\mathrm{Tn}^{+}$mature cells.

\section{Methods}

Patients. After informed consent was obtained, peripheral venous blood $(20-100 \mathrm{ml})$ was collected on preservative free heparin $(3 \mathrm{U} /$ $\mathrm{ml}$ ) on one to four occasions from two patients, Pl. and Ba., with a typical Tn syndrome, who are known to belong to blood group 0 . These patients have been extensively studied before $(7,8,9,10,11)$, and we have previously reported no differences in the percentage of $\mathrm{Tn}^{+}$and $\mathrm{Tn}^{-}$colonies between bone marrow lineages and peripheral blood colonies (10). Therefore, for the convenience of the patient, only the peripheral blood was studied. Peripheral blood was also obtained from normal blood group $O$ volunteers at the Centre National de Transfusion Sanguine, Paris, France.

Cell separation. Peripheral blood from patients Pl. and Ba. was diluted with an equal volume of Hank's balanced salt solution (HBSS) (Eurobio, Paris, France). Light-density nonadherent peripheral blood cells were separated by centrifugation over Ficoll-metrizoate $(d=1.077$, Nyegaard, Oslo, Norway). These cells were washed in cold $\alpha$ medium, followed by an overnight adherence to plastic. Two techniques of separation were subsequently used, both based on interaction of lightdensity nonadherent blood cells with HPA.

HPA recognizes terminal $N$-acetylgalactosamine residues (12) and was used to separate the $\mathrm{Tn}^{+}$and $\mathrm{Tn}^{-}$cells from patients $\mathrm{Pl}$. and $\mathrm{Ba}$.

1. Abbreviations used in this paper: BFU-E, burst-forming-unit erythroid; CFU-GEMM, mixed colony-forming-unit cells; CFU-GM, colonyforming-unit granulocyte macrophage; $\mathrm{Fab}_{2}^{\prime}$, fragment antigen binding; HPA, Helix pomatia agglutinin; LICR-LON-RIO, anti-glycophorin A; $\mathrm{Tn}^{-}, \mathrm{Tn}$ negative; $\mathrm{Tn}^{+}, \mathrm{Tn}$ positive. 
This lectin recognizes A-like determinants. In contrast to Salvia sclarea lectin, the agglutinin HPA is not strictly Tn specific (13), but unfortunately, the former lectin is not presently available in purified form. In normal blood group $O$ subjects, however, the HPA lectin does not recognize any blood or marrow cells (10), and therefore it can be considered as specific for the Tn determinants expressed in our two group $O$ patients.

Cellular affinity chromatography. $20 \times 10^{6}$ light-density mononuclear cells isolated from the peripheral blood of patient PI. were suspended in $2 \mathrm{ml}$ of HBSS containing $0.2 \%$ bovine serum albumin and then applied to a 5-ml column of Helix pomatia Lectin-Sepharose 6 macrobeads (Pharmacia Fine Chemicals, Piscataway, NJ) pre-equilibrated in the same medium under sterile conditions. After application, the cells were incubated on the column with no flow for $15 \mathrm{~min}$ at room temperature. Unbound cells were then eluted with $30 \mathrm{ml}$ of the same medium as above. Bound cells were eluted by washing the column with $30 \mathrm{ml}$ of HBSS containing $1 \mathrm{mg} / \mathrm{ml} \mathrm{N}$-acetyl-D-galactosamine (Sigma Chemical Co., St. Louis, MO).

Fluorescence activated cell sorting. The nonadherent light-density mononuclear cells were labeled by HPA conjugated to fluorescein $\left(1 \mathrm{mg} / \mathrm{ml}\right.$; IBF, Paris, France) using a $10^{-2}$ dilution at $4^{\circ} \mathrm{C}$ in sterile phosphate buffered saline (PBS; $10 \mathrm{mM}$ phosphate buffer, pH 7.2, containing $150 \mathrm{mM} \mathrm{NaCl}$ ) and held on ice until fluorescence-activated cell sorting. The sterile separation of labeled blood cells into positively and negatively stained fractions was performed on a FACS cell sorter (440; Becton-Dickinson \& Co., Oxnard, CA).

The argon ion laser was set to produce light at $488 \mathrm{~nm}$ and at an intensity of $500 \mathrm{~mW}$. Fluorescence was measured through a 520 Long Pass filter. The sheath fluid was PBS, pH 7.2. Sorting was performed through a $50-\mu \mathrm{m}$ nozzle. A $2,000-\mathrm{V}$ deflection potential was selected. The sorting rate was 1,000 cells/s. Sorted cells were collected in $15-\mathrm{ml}$ sterile plastic tubes (Corning Glass Works, Corning, NY) containing 2 $\mathrm{ml}$ of fetal calf serum.

Clonal assay. Burst-forming-unit erythroid (BFU-E), colony-formingunit erythroid (CFU-E), and mixed colony-forming-unit (CFU-GEMM) cells were grown by a modification of the plasma clot technique (14). The medium consisted of $\alpha$ medium (Eurobio, France) supplemented with 10\% human AB serum (Centre Départemental de Transfusion Sanguine, Val-de-Marne, France), $1 \%$ deionized bovine Cohn fraction $\mathrm{V}$ albumin (Sigma), and $34 \mu \mathrm{g} / \mathrm{ml} \mathrm{CaCl}$. Clotting was induced by addition of $10 \%$ bovine citrated plasma (Gibco Laboratories, Grand Island, NY). The stimulating activities were either $5 \%$ supernatant from the Mo-cell line ( $\mathrm{T}$ cell line) containing both burst promoting and granulocyte-macrophage colony stimulating activities $(14,15,16)$ plus $1.5 \mathrm{IU} / \mathrm{ml}$ porcine erythropoietin preparation $(25 \mathrm{IU} / \mathrm{mg}$ of protein, Centre National de Transfusion Sanguine, Paris, France) for the growth of BFU-E or CFU-GEMM, or $10 \%$ supernatant from the Mo-cell line alone for the growth of CFU-GM. In these experiments, $4 \times 10^{5}$ unseparated cells, $5 \times 10^{4}$ to $1 \times 10^{5} \mathrm{Tn}^{+}$cells, and $4 \times 10^{5}$ $\mathrm{Tn}^{-}$cells were plated in $1-\mathrm{ml}$ vol in $35-\mathrm{mm}$ petri dishes (Falcon Labware, Div. of Becton-Dickinson \& Co., Oxnard, CA). Cultures were incubated for $12-14 \mathrm{~d}$ at $37^{\circ} \mathrm{C}$ in a humidified atmosphere containing $5 \% \mathrm{CO}_{2}$ in air.

Immunofluorescent labeling of the cultures. At day 12 or 14, cultures were directly dehydrated in petri dishes with 32-mm filter papers (Whatman Laboratory Products, Inc., Clifton, NJ). A double immunofluorescent labeling was then applied in situ in the dish.

Initially, $300 \mu \mathrm{l}$ of $10^{-2}$ diluted HPA conjugated to fluorescein was applied to the clot for $1 \mathrm{~h}$ at $4^{\circ} \mathrm{C}$. After extensive washings with PBS, $10^{-2}$ diluted ascitic fluid containing a murine monoclonal antibody directed either against glycophorin A (LICR-LON-R10) (17) or against a myeloid antigen (80H5: anti-SSEA-1 antigen) $(18,19)$ was added for $1 \mathrm{~h}$ at $4^{\circ} \mathrm{C}$. After several washings in PBS, the preparations were incubated with a goat anti-mouse immunoglobulin fragment antigen binding ( $\left.\mathrm{Fab}_{2}^{\prime}\right)$ fragment $(3.5 \mathrm{mg} / \mathrm{ml})$ conjugated to tetramethylrhodamine-isothiocyanate (Cappel Laboratories, Cochranville, PA) at a $10^{-2}$ dilution. After subsequent washings, the cultures were fixed with cold methanol for $5 \mathrm{~min}$. The bottom of the petri dish was then cut and the sides of the dish discarded. A 35-mm round glass coverslip was mounted with buffered glycerin on the bottom of the petri dish, which was subsequently stuck on a glass slide. Each preparation was completely scanned under a fluorescent microscope (Carl Zeiss, Inc., Thornwood, NY) equipped with epillumination and appropriate filters for fluorescein, rhodamine, and phase contrast microscopy. Photographs were taken with an Ektachrome ASA 400 film (Eastman Kodak Co., Rochester, NY) push-pulled to ASA 1600.

\section{Results}

Unseparated cells from the two patients gave rise to both $\mathrm{Tn}^{+}$ and $\mathrm{Tn}^{-}$colonies in a proportion comparable to previous published results (10) (Table I). The fluorescent labeling procedure permitted detection of the Tn antigen and identification of all the colonies in each dish. LICR-LON-R10 (anti-glycophorin A) labels erythroid cells from the proerythroblast to the erythrocyte (20) and therefore stains all the BFU-E-derived colonies at day 12-14 of culture (Fig. 1). The monoclonal antibody $80 \mathrm{H} 5$ binds to granulocytic cells from the promyelocyte to the granulocyte (18) and to the monocytic series from the monoblast to the macrophage, and therefore stains all CFU-GM-derived colonies (Fig. 2). Mixed colonies were individualized with the LICR-LON-R10 antibody as colonies containing both erythroid cells (glycophorin-positive cells) and nonerythroid cells (glycophorin-negative cells containing numerous granules or having the typical morphology of monocytemacrophages by phase contrast microscopy). These mixed colonies were considered as clonal since the total number of colonies (erythroid and granulocytic) per dish was $<60$, therefore sustaining culture conditions for a clonal mixed colony assay (21). Scanning of the entire dish with this double fluorescence procedure permits precise determination of the proportion of the $\mathrm{Tn}^{+}$colonies contained in each dish.

Preliminary separation of the blood cells from patient Pl. into $\mathrm{Tn}^{+}$and $\mathrm{Tn}^{-}$fractions was performed by affinity chromatography. $\mathrm{Tn}^{-}$cells did not bind to the column of Sepharose monobeads coupled to HPA. $>100$ CFU-GM were grown from this fraction; all of them were $\mathrm{Tn}^{-}$. However, the $\mathrm{Tn}^{+}$

Table I. Fraction (Percent) of $\mathrm{Tn}^{+}$Progenitors in Colonies as Measured by HPA Labeling

\begin{tabular}{|c|c|c|c|c|}
\hline \multirow[b]{2}{*}{ Patient } & \multirow[b]{2}{*}{ Colonies } & \multirow{2}{*}{$\begin{array}{l}\text { Unseparated } \\
\text { cell } \\
\text { population }\end{array}$} & \multicolumn{2}{|c|}{ Separated cell populations* } \\
\hline & & & $\mathrm{Tn}^{+}$ & $\mathrm{Tn}^{-}$ \\
\hline \multirow{2}{*}{ Pl. Experiment $1 \ddagger$} & BFU-E & 70 & $100(48 / 48)$ & $24(4 / 17)$ \\
\hline & CFU-GM & 60 & $99(77 / 78)$ & $19(4 / 22)$ \\
\hline \multirow{4}{*}{ Experiment $2 \S$} & BFU-E & & $100(140 / 140)$ & $0(0 / 31)$ \\
\hline & CFU-GM & & $100(55 / 55)$ & $0(0 / 9)$ \\
\hline & CFU-GEMM & 65 & $100(25 / 25)$ & $0(0 / 4)$ \\
\hline & BFU-E & 73 & & \\
\hline Ba.‡ & CFU-GM & 75 & $100(13 / 13)$ & $25(6 / 24)$ \\
\hline
\end{tabular}

* Progenitors grown from light-density nonadherent peripheral blood cells separated by fluorescent cell sorting as described in Fig. 4 .

¥ The threshold of fluorescent positivity was determined by analyzing blood mononuclear cells from a blood group $\mathrm{O}$ subject, with a fluoresceinated conjugate of HPA lectin (see Fig. 4). All the cells from the two Tn patients located above or below this threshold fluorescent intensity were respectively collected as $\mathrm{Tn}^{+}$and $\mathrm{Tn}^{-}$fractions.

$\S$ The threshold of positivity was determined as in $¥$. However, the two channels just above this threshold were omitted for the cell collection. Accordingly, $1.5 \%$ of the cells were excluded during the sorting. 


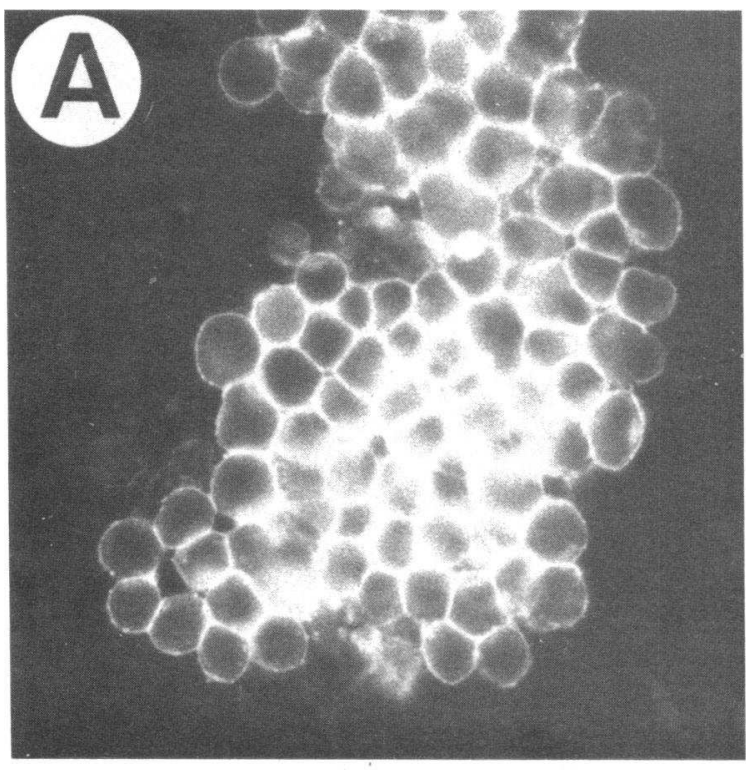

Figure 1. A BFU-E derived colony grown from the $\mathrm{Tn}^{+}$fraction. Nonadherent light-density mononuclear cells from patient Pl. were separated into two fractions with a fluorescent activated cell sorter using the HPA lectin conjugated to fluorescein. $4 \times 10^{4} \mathrm{Tn}^{+}$cells were grown by the plasma clot technique using erythropoietin and Mo-medium as the stimulating factors. At day 14, a double fluores-

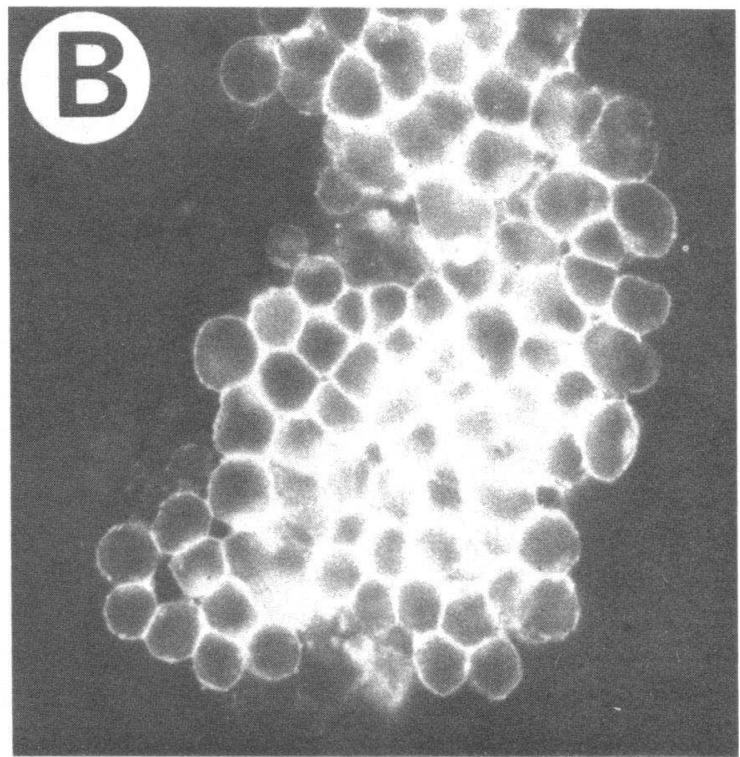

cent procedure was directly applied on the cultures $(\times 583) .(A)$ The erythroblasts composing the colony are labeled with the murine monoclonal antibody LICR-LON-R 10 and revealed with a goat antimouse immunoglobulin $\mathrm{Fab}_{2}$ fragment conjugated to rhodamine. (B) All the erythroblasts are labeled by the HPA lectin conjugated to fluorescein and therefore exhibit the Tn antigen.

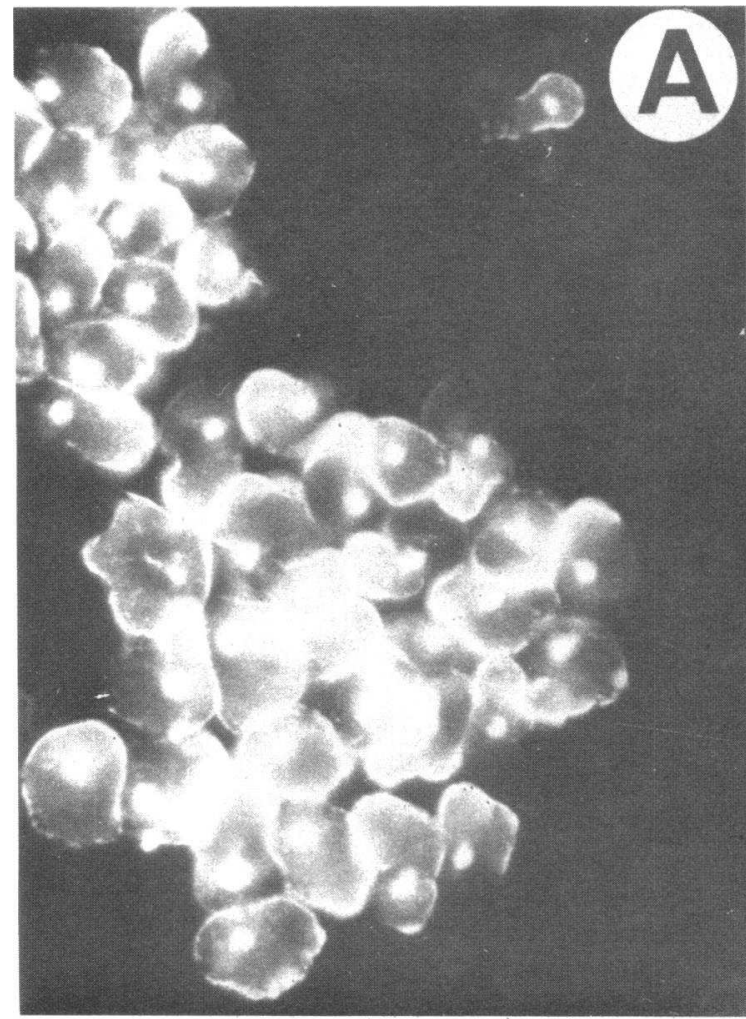

Figure 2. A CFU-GM derived colony grown from the $\mathrm{Tn}^{+}$fraction. The colonies were grown and studied as described in Fig. 1, except that the Mo-medium alone was used as the stimulating factor $(X$ 583). (A) All the granulocytic-monocytic cells are identified by the

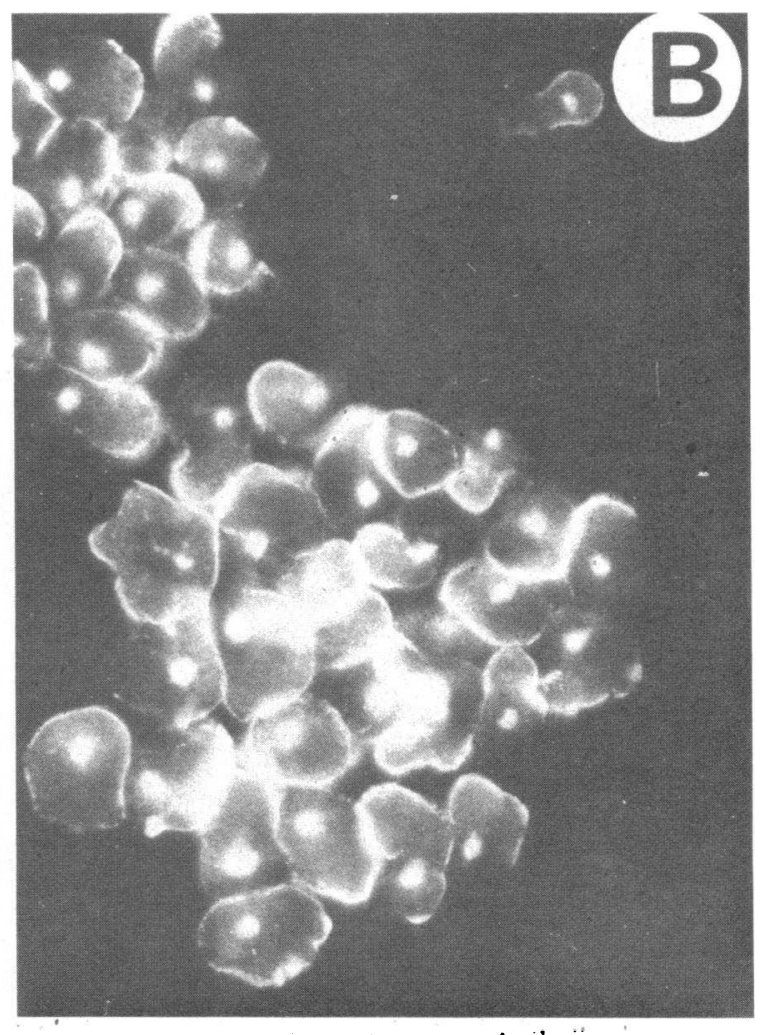

murine monoclonal $80 \mathrm{H} 5$ (anti-SSEA-1 antigen) and revealed with a goat anti-mouse immunoglobulin $\mathrm{Fab}_{2}$ fragment conjugated to rhodamine. $(B)$ All colonies are labeled by the HPA lectin (as in Fig. $1 B$ ) and therefore display the $\mathrm{Tn}$ antigen. 
cells could not be eluted from the column using $N$-acetylgalactosamine.

Cell sorting experiments were subsequently performed. In the first series of experiments, nonadherent light-density mononuclear blood cells from patients $\mathrm{Pl}$. and $\mathrm{Ba}$. were separated into $\mathrm{Tn}^{+}$and $\mathrm{Tn}^{-}$fractions and subsequently cultured. The threshold of positivity was determined using HPA-labeled mononuclear blood cells from a normal $O$ patient. In both patients, two subpopulations of cells were clearly present among the mononuclear blood cells. One was positively labeled with HPA, the other was not. The positive fraction represented 12 and $15 \%$ of the nonadherent light-density mononuclear cells for patients $\mathrm{Pl}$. and $\mathrm{Ba}$., respectively. This low percentage of HPA positive mononuclear blood cells in the two patients is explained by the high frequency $(60-75 \%)$ of $T$ lymphocytes in this cell fraction. Indeed, we have shown previously that $<1 \% \mathrm{~T}$ lymphocytes from patients $\mathrm{Pl}$. and $\mathrm{Ba}$. exhibit the Tn antigen (11). The percentage of $\mathrm{Tn}^{+}$cells, therefore, reflects the proportion of $\mathrm{Tn}^{+} \mathrm{B}$ cells and monocytes (11).

In both patients, the $\mathrm{Tn}^{+}$fractions give rise to nearly $100 \%$ positive colonies (Table I). As previously demonstrated (10), these colonies were composed exclusively of $\mathrm{Tn}^{+}$cells (Figs. $1,2)$. The $\mathrm{Tn}^{-}$fraction gave rise to $75-81 \%$ negative colonies composed only of $\mathrm{Tn}^{-}$cells (Fig. 3).

In patient $\mathrm{Pl}$. the number of colonies per $10^{5}$ unseparated mononuclear blood cells was 32, 18, and 5 for BFU-E, CFUE, and CFU-GM and CFU-GEMM, respectively. $62 \%$ of the total number of colonies were recovered from the $\mathrm{Tn}^{+}$fraction while $38 \%$ were grown from the $\mathrm{Tn}^{-}$fraction. This result agreed with the data obtained on unfractionated cells where
$65 \%$ of the colonies were $\mathrm{Tn}^{+}$and $35 \%$ were $\mathrm{Tn}^{-}$. Furthermore, the addition of the colonies recovered in the two fractions (i.e., $\mathrm{Tn}^{+}$and $\mathrm{Tn}^{-}$) was nearly equal (90-95\%) to the number of colonies grown from the same number of unfractionated cells, excluding that the separation procedure by itself might have abolished the growth of one population of progenitors $\left(\mathrm{Tn}^{+}\right.$or $\left.\mathrm{Tn}^{-}\right)$. A similar result was found for patient $\mathrm{Ba}$. It was obvious, therefore, that the $\mathrm{Tn}^{+}$and $\mathrm{Tn}^{-}$colonies were not randomly distributed between the two fractions (random hypothesis, $\mathrm{X}^{2}=48.5$, d.f. $=1, P<0.0005$ ).

The presence of some $\mathrm{Tn}^{+}$colonies in the $\mathrm{Tn}^{-}$fraction was considered to result from difficulty in determining the exact threshold of fluorescence positivity. In a second set of experiments (Table I, patient Pl.), cells that displayed a fluorescence intensity at the threshold of positivity, i.e., 2 channels out of 255 (Fig. 4), were omitted from the sorting procedure. $6 \times 10^{5}$ cells were sorted as positive, while $58 \times 10^{5}$ were $\mathrm{Tn}^{-}$. In this case, the $\mathrm{Tn}^{+}$and $\mathrm{Tn}^{-}$fractions only gave rise to $\mathrm{Tn}^{+}$or $\mathrm{Tn}^{-}$colonies, respectively.

\section{Discussion}

Previous results from our group have clearly established that the Tn syndrome is a clonal disease since the Tn abnormality is clonally expressed in colonies from the different hemopoietic lineages, i.e., granulocytic, erythroid, and megakaryocytic lineages (10). The mutation affects a stem cell common to the myeloid and lymphoid lineages including the $B$ and $T$ series, since lymphocytes are also involved by this disorder (11). However, a strikingly low percentage of $T$ cells expressing the

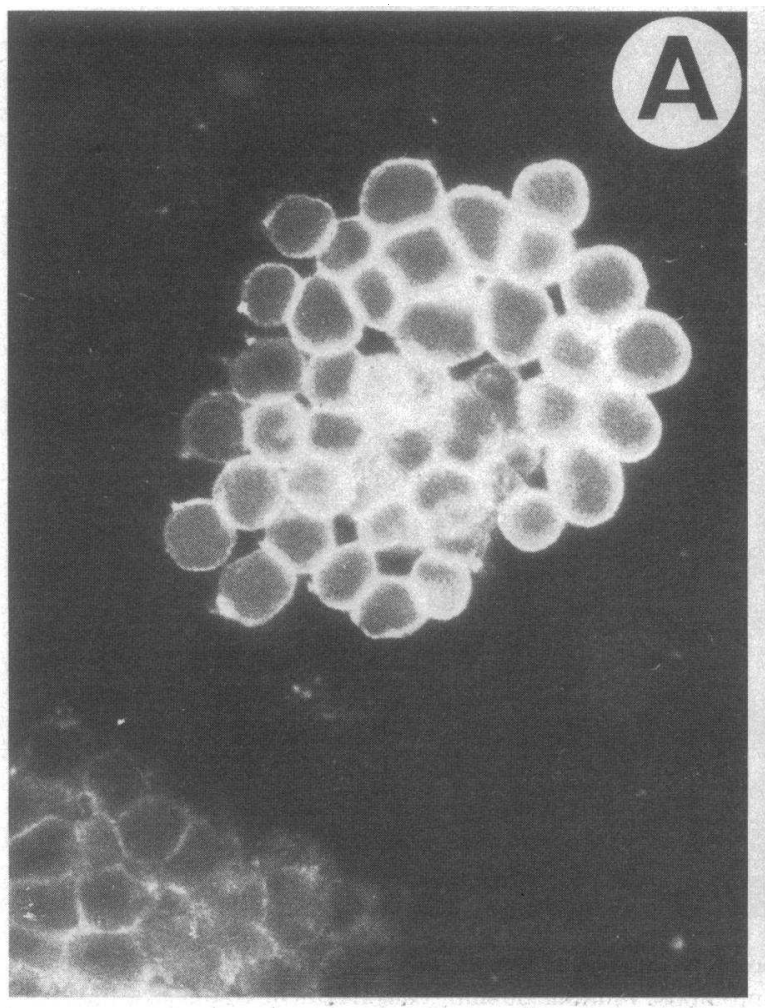

Figure 3. A BFU-E derived colony grown from the $\mathrm{Tn}^{-}$fraction. The colonies were grown and studied as in Fig. 1. However, in this experiment, the $\mathrm{Tn}^{-}$cells were grown at a $4.10^{5}$-cells $/ \mathrm{ml}$ concentration $(\times 583) .(A)$ The erythroblasts are identified by the antiglyco-

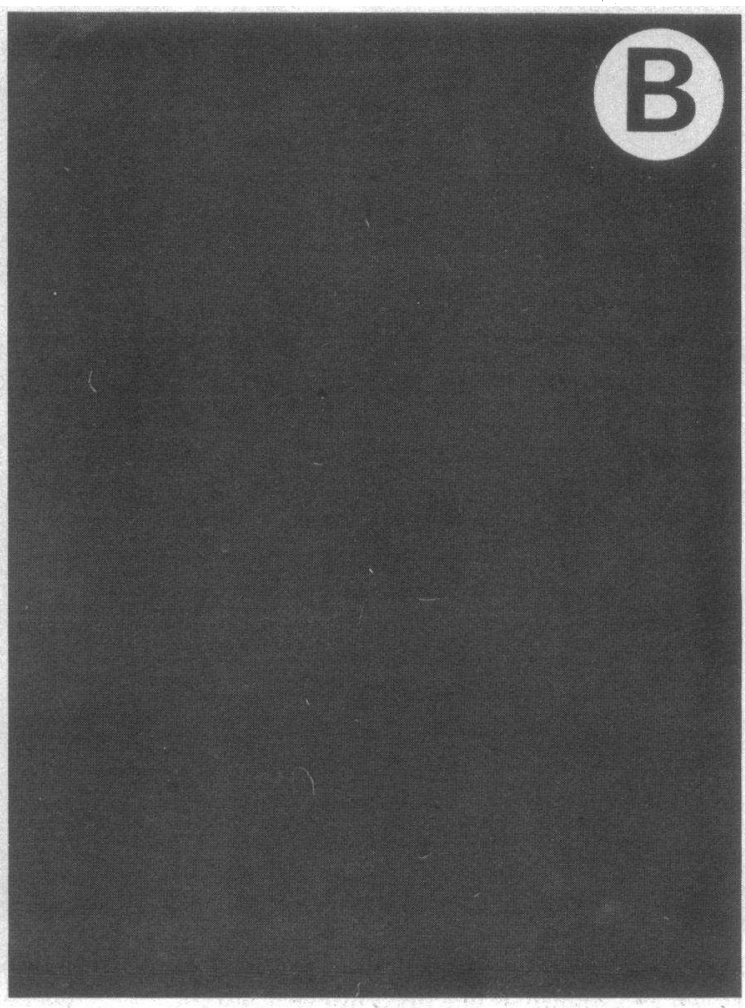

phorin antibody (as in Fig. $1 A$ ). (B) The colony is not labeled by the fluorescent conjugate of HPA agglutinin and therefore is considered as $\mathrm{Tn}^{-}$. 


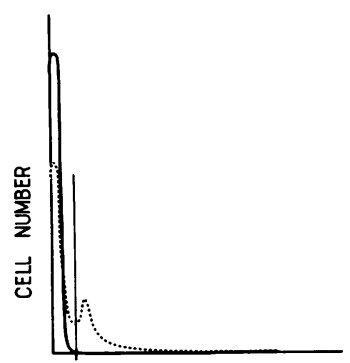

NTENSITY OF FLUORESCENCE
Figure 4. Linear analysis of the fluorescence intensity of light-density nonadherent peripheral blood cells from control group $\mathrm{O}(-)$ and from Tn patient Pl. (- - ) after direct labeling with a fluorescent conjugate of Helix pomatia lectin. In patient Pl., there are clearly two populations of light density mononuclear cells; one negative, which is superimposed on the $\mathrm{O}$ control, the other positive. Positive cells were sorted to the right of the bar, and negative cells were sorted to the left. The two channels placed on each side of the bar were not used for sorting.

Tn antigen was observed (11). This result was considered to be due to either the long life of these $T$ cells or their origin in a $T$ cell precursor independent of the multipotential stem cells, having self-renewal capacities.

In this study, direct evidence demonstrates the presence of the Tn antigen on the stem cells of the Tn clone. Thus, $\mathrm{Tn}^{+}$ progenitors (BFU-E, CFU-GM, and CFU-GEMM) give rise unequivocally to $\mathrm{Tn}^{+}$colonies, and $\mathrm{Tn}^{-}$progenitors to $\mathrm{Tn}^{-}$ colonies.

Previous flow sorting approaches of hemopoietic progenitors using monoclonal antibodies against differentiation antigens have underlined the difficulties of the separation (22). Indeed, most of these antibodies give a broad distribution of staining. Difficulties of interpretation were avoided by taking into account, on the one hand, a clear positive population of cells, and on the other hand, a population considered as negative but still expressing low amounts of antigens detected by the fluorescent antibody (22).

In contrast, this study has taken advantage of the two populations of hemopoietic cells present in Tn individuals; one bears the Tn antigen, whereas the other lacks it. There is still a doubt concerning the exact threshold of positivity selected for sorting. This difficulty can be overcome by specific collection of distinctly positive or negative cells.

As pointed out, the Tn transformation can be compared with the paroxysmal nocturnal hemoglobinuria (23-27). In both diseases, two populations of hemopoietic cells are found; acute leukemia may also occur. As presently demonstrated in the Tn syndrome, Dessypris et al. (27) have recently shown that the hemopoietic progenitors of the paroxysmal nocturnal hemoglobinuria syndrome carry the same membrane abnormality that is present on mature cells, i.e., a hypersensitivity to lysis by complement. The defect responsible for this abnormality is partially known, since Nicholson-Weller et al. (28) have shown recently that paroxysmal nocturnal hemoglobinuria erythrocytes are deficient in decay accelerating factor, a complement regulatory protein that decreases the stability of $C_{3}$ convertase on red cells.

The biochemical defect occurring in the Tn syndrome is well characterized and apparently consists of a loss of activity of a specific glycosyltransferase $(7,9)$. This abnormality seems to be isolated and involves the carbohydrate composition of the cell surface glycoproteins from hemopoietic cells. Therefore, the carbohydrate structure of the $\mathrm{Tn}$ antigen might play a crucial role in the regulation of the pluripotent stem cells, and the unmasking of this determinant on the $\mathrm{Tn}^{+}$clone may be responsible for its proliferative advantage. Further studies on long-term bone-marrow cultures will be necessary to demonstrate this hypothesis.

\section{Acknowledgments}

We should like to thank P. Mannoni and P. A. W. Edwards for their generous gift of monoclonal antibodies, and Dr. D. Golde for the gift of Mo-medium. We are indebted also to J. Chapman for assistance in reviewing the manuscript.

\section{References}

1. Bird, G. W. G. 1977. Erythrocyte polyagglutination. In Clinical Laboratory Science. T. J. Greenwalt and E. A. Steane, editors. CRC Press Inc., Cleveland, OH. 1:443-454.

2. Bird, G. W. G., N. K. Shinton, and J. Wingham. 1971. Persistent mixed-field polyagglutination. Br. J. Haematol. 21:443-453.

3. Bird, G. W. G., J. Wingham, M. J. Pippard, J. G. Hoult, and V. Melikian. 1976. Erythrocyte membrane modification in malignant diseases of myeloid and lymphoreticular tissues. Br. J. Haematol. 33:289-294.

4. Baldwin, M. L., C. Barrasso, and R. I. Ridolfi. 1979. Tnpolyagglutinability associated with acute myelo-monocytic leukemia. Am. J. Clin. Pathol. 72:1024-1027.

5. Ness, P. M., G. Garraty, P. A. Morel, and H. A. Perkins. Tnpolyagglutination preceding acute leukemia. Blood. 54:30-34.

6. Dahr, W., G. Uhlenbruck, and G. W. G. Bird. 1974. Cryptic Alike receptor sites in human erythrocyte glycoproteins proposed nature of the Tn antigen. Vox Sang. 27:29-42.

7. Cartron, J. P., G. Andreu, J. Cartron, G. W. G. Bird, C. Salmon, and A. Gerbal. 1978. Demonstration of T-transferase deficiency in Tnpolyagglutinable blood samples. Eur. J. Biochem. 92:111-119.

8. Cartron, J. P., and A. T. Nurden. 1979. Galactosyltransferase and membrane glycoprotein abnormality in human platelets from $\mathrm{Tn}$ syndrome donors. Nature (Lond.). 282:621-623.

9. Cartron, J. P., J. Cartron, G. Andreu, C. Salmon, and G. W. G. Bird. 1978. Selective deficiency of 3- $\beta$-D-galactosyltransferase (T-transferase) in Tn-polyagglutinable erythrocytes. Lancet. 1:856-857.

10. Vainchenker, W., U. Testa, J. F. Deschamps, A. Henri, M. Titeux, J. Breton-Gorius, H. Rochant, D. Lee, and J.-P. Cartron. 1982. Clonal expression of the $\mathrm{Tn}$ antigen in erythroid and granulocyte colonies and its application to determination of the clonality of the human megakaryocyte colony assay. J. Clin. Invest. 69:1081-1091.

11. Brouet, J. C., W. Vainchenker, D. Blanchard, U. Testa, and J. P. Cartron. 1983. The origin of human B and T cells from multipotent stem cells: a study of the Tn syndrome. Eur. J. Immunol. 13:350-352.

12. Hammarström, S., L. A. Murphy, I. J. Goldstein, and M. E. Metzler. 1977. Carbohydrate binding specificity of four N-acetyl-Dgalactosamine-"specific" lectins: Helix pomatia A hemagglutinin, soy bean agglutinin, lima bean lectin and Dolichos biflorus lectin. Biochemistry. 16:2750-2755.

13. Bird, G. W. G., and J. Wingham. 1974. The M, N and Nvg receptors of Tn erythrocytes. Vox Sang. 26:171-175.

14. McLeod, D. L., M. M. Shreeve, and A. A. Axelrad. 1974. Improved plasma culture system for production of erythrocytic colonies in vitro: quantitative assay method for CFU-E. Blood. 44:517-534.

15. Golde, D. W., N. Bersch, S. G. Quan, and A. J. Lusis. 1980. Production of erythroid potentiating activity by a human T-lymphoblast cell line. Proc. Natl. Acad. Sci. USA. 77:593-596.

16. Lusis, A. J., D. H. Quan, and D. W. Golde. Purification and characterization of a human T-lymphocyte derived granulocyte macrophage colony stimulating factor. Blood. 57:13-21.

17. Edwards, P. A. W. 1980. Monoclonal antibodies that bind to the human erythrocyte membrane glycoproteins glycophorin and band 3. Biochem. Soc. Trans. 8:334-335.

18. Mannoni, P., A. Janowska-Wieczorek, K. Turner, L. McGann, 
and J. M. Turc. 1982. Monoclonal antibodies against human granulocytes and myeloid differentiation antigens. Hum. Immunol. 5:309323.

19. Gooi, H. C., S. J. Thorpe, E. F. Hounsell, H. Rumpold, D. Kraft, O. Förster, and T. Feizi. 1983. Marker of peripheral blood granulocytes and monocytes of man recognized by two monoclonal antibodies VEP8 and VEP9 involves the trisaccharide 3-fucosyl- $N$ acetylactosamine. Eur. J. Immunol. 13:306-312.

20. Robinson, J., C. Sieff, D. Delia, P. A. W. Edwards, and M. Greaves. 1981. Expression of cell surface HLA-DR, HLA-ABC and glycophorin during erythroid differentiation. Nature (Lond.). 289:6870.

21. Powell, J. S., P. J. Fialkow, and J. W. Adamson. 1982. Polycythemia vera: studies of hemopoiesis in continuous long term culture of human marrow. J. Cell. Physiol. (Suppl 1):79-85.

22. Sieff, C., D. Bicknell, G. Caine, J. Robinson, G. Lam, and M. F. Greaves. 1982. Changes in cell surface antigen expression during hemopoietic differentiation. Blood. 60:703-713.

23. Rosse, W. F., and J. V. Dacie. 1966. Immune lysis of normal human and paroxysmal nocturnal hemoglobinuria (PNH) red blood cells. I. The sensitivity of PNH red cells to lysis by complement and specific antibody. J. Clin. Invest. 45:736-748.

24. Stern, M., and W. F. Rosse. 1979. Two populations of granulocytes in paroxysmal nocturnal hemoglobinuria. Blood. 53:928934.

25. Aster, R. H., and S. E. Enright. 1969. A platelet and granulocyte membrane defect in paroxysmal nocturnal hemoglobinuria. Usefulness for detection of platelet antibodies. J. Clin. Invest. 48:1199-1210.

26. Oni, S. B., B. O. Osunkoya, and L. Luzzatto. 1970. Paroxysmal nocturnal hemoglobinuria evidence for monoclonal origin of abnormal red cells. Blood. 36:145-152.

27. Dessypris, E. N., D. A. Clark, C. McKee, Jr., and S. B. Krantz. 1983. Increased sensitivity to complement of erythroid and myeloid progenitors in paroxysmal nocturnal hemoglobinuria. $N$. Engl. J. Med. 309:690-693.

28. Nicholson-Weller, A., J. P. March, S. Rosenfeld, and K. F. Austen. 1983. Affected erythrocytes of patients with paroxysmal nocturnal hemoglobinuria are deficient in the complement regulatory protein, decay accelering factor. Proc. Natl. Acad. Sci. USA. 80:50665070. 